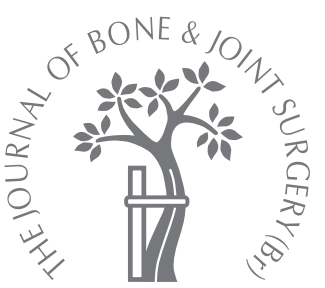

S. Y. Joo,

K. B. Park,

B. R. Kim,

H. W. Park,

H. W. Kim

From the Severance Children's Hospital, Seoul, Korea

\title{
The 'four-in-one' procedure for habitual dislocation of the patella in children
}

\author{
EARLY RESULTS IN PATIENTS WITH SEVERE GENERALISED \\ LIGAMENTOUS LAXITY AND APLASIS OF THE TROCHLEAR \\ GROOVE
}

\begin{abstract}
S. Y. Joo, MD, Clinical Fellow B. R. Kim, MD, Clinical Fellow H. W. Kim, MD, PhD, Associate Professor Department of Orthopaedic Surgery

Severance Children's Hospital, Yonsei University College of Medicine, 250 Seongsanno, Seodaemun-Gu, Seoul 120 752 , Korea.

K. B. Park, MD, Lecturer Department of Orthopaedic Surgery

Hallym University College of Medicine, 896 PyeongchonDong, Dongam-Gu, Anyang, Korea.
\end{abstract}

H. W. Park, MD, Professor Department of Orthopaedic Surgery

Yongdong Severance Hospital, Yonsei University College of Medicine, 612 Eonjuro, Kangnam-Gu, Seoul 135-720, Korea.

Correspondence should be sen to Professor H. W. Kim; e-mail: pedhkim@yuhs.ac.kr

(C)2007 British Editorial Society of Bone and Joint Surgery doi:10.1302/0301-620X.89B12. $19398 \$ 2.00$

$J$ Bone Joint Surg [Br] 2007;89-B:1645-9. Received 5 March 2007; Accepted after revision 4 June 2007

\begin{abstract}
We describe our experience with the 'four-in-one' procedure for habitual dislocation of the patella in five children (six knees). All the patients presented with severe generalised ligamentous laxity and aplasia of the trochlear groove. All had a lateral release, proximal 'tube' realignment of the patella, semitendinosus tenodesis and transfer of the patellar tendon. The mean age at the time of the operation was 6.1 years (4.9 to 6.9), and the patients were followed up for a mean of $\mathbf{5 4 . 5}$ months (31 to 66). The clinical results were evaluated using the Kujala score.

There has been no recurrence of dislocation. All the patients have returned to full activities and the parents and children were satisfied with the clinical results. The mean Kujala score was 95.3 (88 to 98). Two patients had marginal skin necrosis which healed after debridement and secondary closure. These early results in this small group have shown that the 'four-in-one' procedure is effective in the treatment of obligatory dislocation of the patella in children with severe ligamentous laxity and trochlear aplasia.
\end{abstract}

'Congenital' dislocation of the patella describes an irreversible dislocation present since birth. The term 'habitual' or 'obligatory' dislocation is preferred for patients in whom the patella moves in and out of its normal position in the trochlear groove whenever the knee is flexed or extended. ${ }^{1}$ It usually presents after the child starts to walk, and is often tolerated in childhood, if it is not painful. However, it may present in childhood with dysfunction and instability. The patella usually dislocates laterally in flexion and relocates in extension, but the opposite can occur. ${ }^{2}$

Many surgeons suggest that rebalancing of the patella in habitual dislocation should be performed when the patient is older unless the condition is interfering with activities of daily life. ${ }^{1}$ However, because the trochlear groove is hypoplastic, instability of the patellofemoral joint can become an increasing problem as the patient grows. Pain and degenerative arthritis may develop later, particularly in adolescent girls with recurrent dislocation of the patella. ${ }^{3}$

We have reviewed the early results of the use of the 'four-in-one' procedure in younger children in whom patellar dislocation was associated with severe ligamentous laxity and aplasia of the trochlear groove, but without malalignment or malrotation of the leg. The procedure included lateral release, proximal 'tube' realignment of the patella, ${ }^{4}$ semitendinosus tenodesis, and transfer of the patellar tendon.

\section{Patients and Methods}

The study included six knees in five patients (Table I). All were girls and one had undergone the procedure on both knees. Down's syndrome was present in two patients and William's syndrome in one. No patient had a history of trauma or previous operation associated with dislocation. All the patellae dislocated easily with or without pain at $15^{\circ}$ to $25^{\circ}$ of knee flexion both actively and passively. In all patients frequent dislocations caused considerable problems such as anterior knee pain, recurrent falls and extensor weakness in spite of the use of patellar stabilising braces. The mean age of the patients at the time of surgery was 6.1 years (4.6 to 6.9 ).

None of the patients presented with a knee flexion contracture or an extension lag. Severe generalised ligamentous laxity was scored according to the classification of Beighton, Solomon and Soskolne. ${ }^{5}$ All the patients had a score of seven or more and the patellae were small, hypoplastic and hypermobile. ${ }^{6}$ None of the patients showed malalignment or malrotation. The mean mechanical axis was $8^{\circ}$ of valgus $\left(6^{\circ}\right.$ to $\left.9^{\circ}\right)$. The mean femoral anteversion and external tibial rotation measured by CT was $22^{\circ}\left(12^{\circ}\right.$ to $\left.26^{\circ}\right)$ and $17^{\circ}\left(14^{\circ}\right.$ to $\left.21^{\circ}\right)$, respectively. Plain radiographs showed no evidence of patella alta as defined by Insall and Salvati. ${ }^{7}$ Examination at surgery showed that 
Table I. Clinical details of the patients and the results

\begin{tabular}{|c|c|c|c|c|c|c|c|c|c|c|}
\hline \multirow[b]{2}{*}{ Case } & \multirow[b]{2}{*}{$\begin{array}{l}\text { Age } \\
\text { (yrs) }\end{array}$} & \multirow[b]{2}{*}{ Side } & \multirow[b]{2}{*}{ Comorbidity } & \multirow[b]{2}{*}{$\begin{array}{l}\text { Length of } \\
\text { follow-up (mths) }\end{array}$} & \multicolumn{2}{|c|}{ Kujala grading ${ }^{9}$} & \multicolumn{2}{|c|}{ Dejour classification ${ }^{11}$} & \multirow[b]{2}{*}{$\begin{array}{l}\text { Sulcus angle }\left({ }^{\circ}\right) \\
\text { at final follow-up }\end{array}$} & \multirow[b]{2}{*}{ Complications } \\
\hline & & & & & Score* & Result & $\begin{array}{l}\text { Pre- } \\
\text { operative }\end{array}$ & $\begin{array}{l}\text { Final } \\
\text { follow-up }\end{array}$ & & \\
\hline 1 & 6.9 & Left & Down's syndrome & 63 & 88 & Good & $\mathrm{B}$ & $A$ & 144.1 & None \\
\hline 2 & 6.8 & Left & William's syndrome & 66 & 96 & Excellent & $\mathrm{C}$ & $A$ & 155.5 & None \\
\hline 3 & 5.4 & Left & None & 61 & 98 & Excellent & C & $A$ & 142.2 & $\begin{array}{l}\text { Marginal skin } \\
\text { necrosis }\end{array}$ \\
\hline 3 & 6.3 & Right & None & 51 & 98 & Excellent & $\mathrm{C}$ & $A$ & 156.1 & None \\
\hline 4 & 6.8 & Right & None & 55 & 96 & Excellent & $\mathrm{C}$ & $A$ & 145.3 & None \\
\hline 5 & 4.6 & Left & Down's syndrome & 31 & 96 & Excellent & $\mathrm{C}$ & $A$ & 145.9 & $\begin{array}{l}\text { Marginal skin } \\
\text { necrosis }\end{array}$ \\
\hline
\end{tabular}

* outcomes were evaluated at the final follow-up

the trochlear groove was not fully formed and the cartilaginous intercondylar notch was convex anteriorly in all patients.

Operative technique. The procedures were performed in all the children by a single surgeon (HWK). A conventional curvilinear medial parapatellar incision is made to expose the entire quadriceps mechanism, including the patellar tendon. The lateral tether is released by dividing the fibrous adhesions which extend along the lateral intermuscular septum. The lateral patellar retinaculum and the synovium are divided, and vastus lateralis detached from the quadriceps tendon, leaving a rim of tendon for suturing. Vastus medialis is detached by a second incision and the muscle carried distally and repositioned to cross the patella. The quadriceps expansion is then shaved from the medial third of the patella and extended distally along the medial border of the patellar ligament.

Deep to the medial side of the skin flap, the sartorius, gracilis and semitendinosus are exposed. The semitendinosus tendon is preserved distally and divided at its musculotendinous junction. The tendon is then followed to its insertion posterior to the sartorius and gracilis tendons, freeing all extraneous attachments. Contrary to the method of drilling obliquely across the patella in the line of the tenodesis, ${ }^{8}$ the tendon is pulled across the surface of the patella which is then positioned centrally in the aplastic trochlear groove. With the knee flexed to $30^{\circ}$, the portion of the semitendinosus tendon abutting the superolateral corner of the patella is sutured under tension using a non-absorbable anchoring screw. The remaining tendon is sutured to the periosteum of the patella with an absorbable running suture in the line of the tenodesis (Fig. 1a).

Next, beginning proximally, vastus medialis is brought laterally and sutured to the free edge of vastus lateralis, forming a 'tube' as described by Insall et al. ${ }^{4}$ When the repair reaches the proximal pole of the patella, we try to rotate the patella medially. At the same time, the tendon of vastus lateralis which usually feels tight is lengthened by Z-plasty. The medial flap is sutured, the suture line becoming somewhat oblique across the patella towards the tibial tubercle (Fig. 1b). As a result of these procedures, the patella can be relocated in the aplastic femoral trochlear groove with a range of movement from full extension to approximately $70^{\circ}$ of flexion without subluxation.

The final step is to realign the insertion of the patellar tendon more medially. Its lateral half is split longitudinally from the medial half and passed medially under the medial half of the tendon. The tendon is then reattached to the periosteum providing distal and medial advancement (Fig. 1c). The tension applied to the tendon is then fine tuned, so that full passive knee flexion without subluxation is possible.

A long-leg cast was applied with the knee in $20^{\circ}$ of flexion for six weeks, during which the patients were encouraged to do vigorous quadriceps-strengthening exercises. A long-leg brace was then applied to limit knee flexion. The degree of flexion allowed was gradually increased with time, depending on the stability of the patella and the strength of quadriceps.

Each child and parent was asked to fill out a questionnaire to evaluate the post-operative results which were scored according to the criteria of Kujala et al. ${ }^{9}$ Weight-bearing anteroposterior and lateral radiographs of the knee were taken and a skyline or Merchant view was used to evaluate the patellofemoral relationship. It was impossible to measure the sulcus angle at the time of operation because of aplasia of the trochlear groove ${ }^{10}$ (Fig. 2), the severity of which was measured using the classification of Dejour et al. ${ }^{11}$

\section{Results}

The mean follow-up was 54.5 months (31 to 66). There were no episodes of recurrent patellar dislocation during this time. The mean Kujala score at the most recent follow-up was 95.3 points (88 to 98) (Table I). Both the children and the parents were satisfied with the outcome. Three children were able to return to regular activities 12 months after operation and two after 14 months. All had normal patellar tracking. One patient complained of anterior knee pain after vigorous activity. The patella in one of the patients with Down's syndrome could be dislocated by forceful lateral stress. However, dislocation did not occur through the full range of voluntary knee movement. Two patients suffered marginal skin necrosis which eventually healed after debridement and secondary closure. Radiographs showed no evidence of patella alta in any of the patients and all patellae were centrally located in 


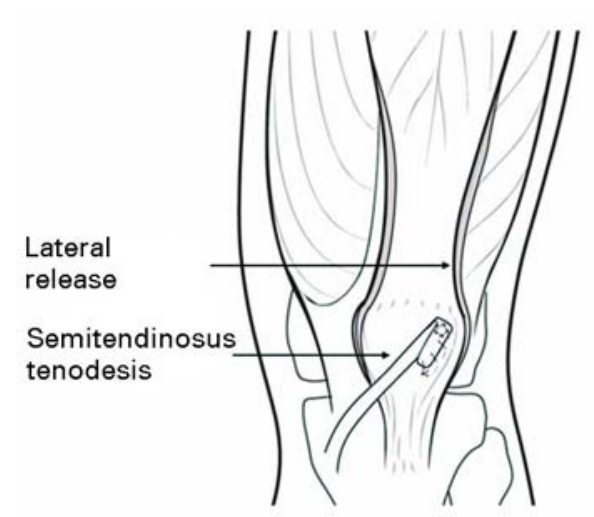

Fig. 1a

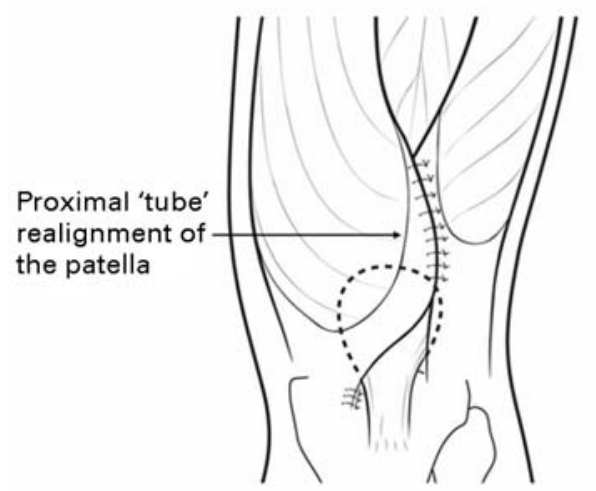

Fig. 1b

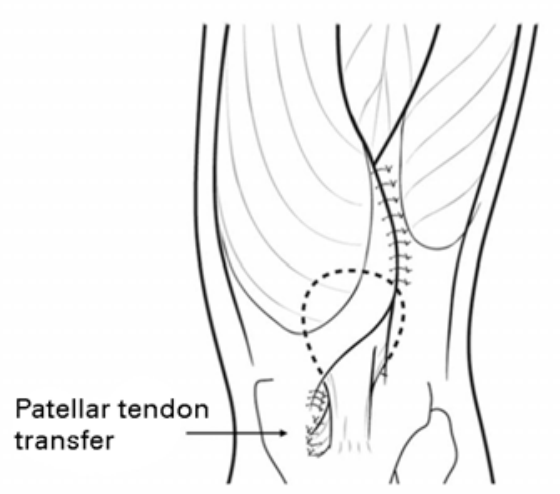

Fig. 1c

Diagrams of the 'four-in-one' procedure showing a) lateral release and semitendinosus tenodesis, b) proximal 'tube' realignment and c) transfer of the patellar tendon.

the intercondylar notch as shown on the skyline or Merchant view. Pre-operatively all femoral trochleae had been classified as Dejour group B or C, but at the final follow-up all were group A (Table I, Fig. 3). The mean sulcus angle at the final follow-up was $148.2^{\circ}\left(142.2^{\circ}\right.$ to $\left.156.1^{\circ}\right)$.

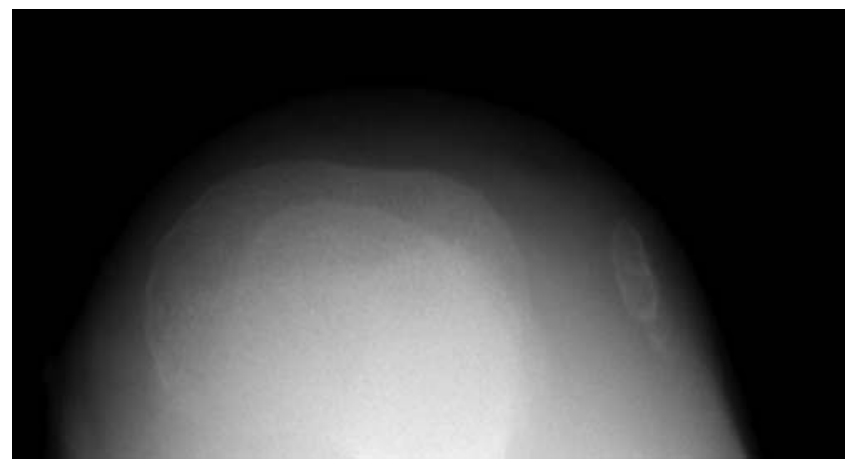

Fig. 2

The pre-operative skyline view of a five-year-old girl with habitual dislocation of the patella showing dislocation of the patella and aplasia of the trochlear groove.

\section{Discussion}

In both recurrent and habitual dislocation of the patella softtissue anomalies such as contracture of the lateral soft tissues around the patella, quadriceps contracture and atrophy of vastus medialis obliquus can occur. Bony abnormalities such as hypoplasia of the femoral trochlear groove, genu valgum, increased femoral anteversion and/or external tibial torsion and a high-riding patella are also predisposing factors. ${ }^{12}$ Many surgical techniques have been proposed and the outcome of treatment of recurrent dislocation of the patella in adolescents and adults has recently been improved with the use of newer methods of reconstruction ${ }^{13,14}$ including those involving the medial patellofemoral ligament. ${ }^{15,16}$ However, none of the techniques has been uniformly successful in preventing dislocation, with a reported incidence of unsatisfactory results of $20 \%$ to $80 \% .^{4,11,17-22}$

Traditionally, habitual dislocation has been treated in the same way as recurrent dislocation, except for the need for lengthening of the quadriceps tendon. Most authors have reported habitual dislocation in association with shortening of the quadriceps muscles, and consider that lengthening of the tendon is an essential part of the procedure to allow the patella to remain reduced after realignment. ${ }^{2}$ Contrary to these findings, we have found that normal patellar tracking was maintained in our patients without lengthening of the quadriceps tendon.

Patellar instability associated with abnormal ligamentous laxity presents a considerable challenge. In patients with Down's syndrome the indication for patellar stabilisation has been questioned because of the frequent absence of symptoms or functional problems. ${ }^{23}$ The parents and children must be advised of the abnormal nature of their collagen and must recognise that surgical correction may not overcome this genetic predisposition to instability. However, in our study all the patients had significant symptoms and were unable to walk comfortably from an early age. It is possible 


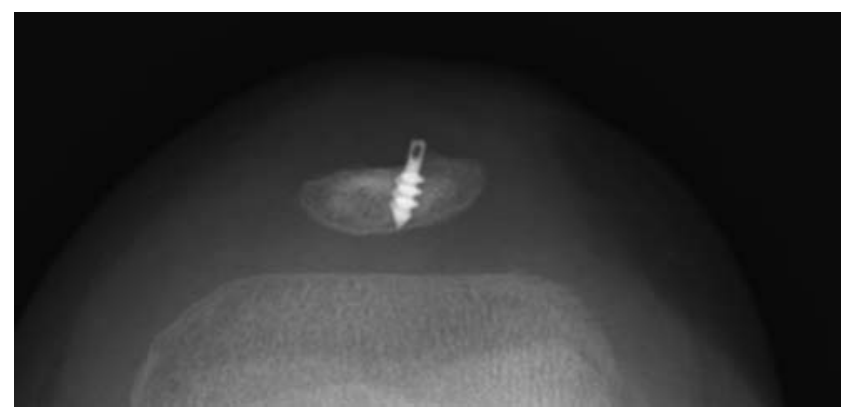

Fig. 3a

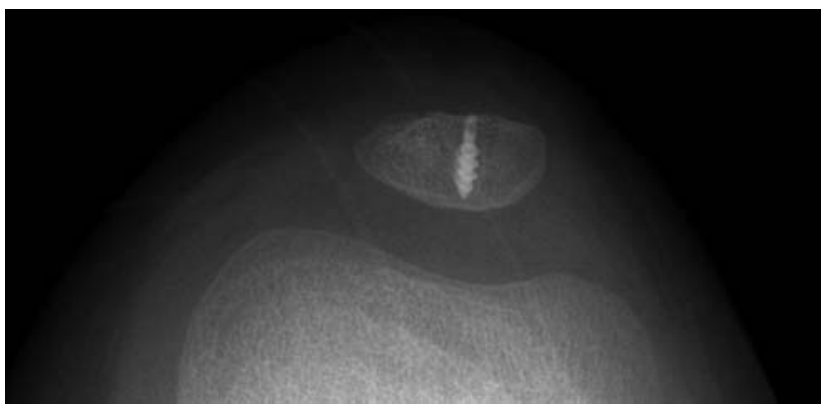

Fig. 3b

Radiographs of the skyline view showing a) a satisfactory location of the patella in the trochlear groove eight months after operation and b) a welldeveloped trochlear groove four years after operation.

that chronic habitual dislocation in these patients may lead to patellofemoral arthritis, by which time reconstructive procedures for long-standing insufficiency of the quadriceps and peri-articular soft-tissue may not be successful.

In a growing child, surgical options for the transfer of the origin of the patellar tendon are limited by the open growth plate. Some authors have commented that depending on the degree of quadriceps dysfunction, lateral retinacular release, medial vector augmentation and patellar tendon alignment should be combined. ${ }^{24-26}$ In children with generalised ligamentous laxity, the Insall technique of proximal tube realignment of the patella ${ }^{4}$ would seem to be preferable to the method of detaching and advancing vastus medialis. In our study we found the lateral patellar retinaculum, fascial bands and vastus lateralis to be very tight and vastus medialis so deficient that sufficient muscle advancement was not possible. The Insall technique provided a secure repair which reduced the tension of the suture line to a minimum in our patients.

Since it was introduced by Galeazzi, ${ }^{27}$ semitendinosus tenodesis of the patella has been popular, especially in children with an open growth plate..$^{8,17,18}$ Although the tendon traditionally passes through the patella in the line of the tenodesis, we positioned it across the surface of the patella and sutured it to the superolateral corner using a non-absorbable anchoring screw. This was done because there was insufficient length of the tendon to be able to pass it through the patella and to sew it back on to itself in any of our patients. This was contrary to the findings of others that the tendon is usually normal in length. Although the criteria for the assessment of results vary among studies, the overall satisfactory results of semitendinosus tenodesis have ranged between $62 \%$ and $88 \%{ }^{8,17,18}$ However, in these studies the mean age of the patients was 14 years (4 to 30 ) with most being adolescents. Most studies report poor results in patients with ligamentous laxity, with a recurrent rate of dislocation during follow-up of between $27 \%$ and $100 \% .{ }^{17,22,28}$ This may be because many of the patients had, as well as generalised ligamentous laxity, an increased Q-angle and patella alta, which were not corrected at the initial operation. There is also controversy as to whether the isometricity of the transferred tendon is maintained during knee movement. At the last follow-up all our patients showed a relatively mobile patella in full extension of the knee and in only one could it be dislocated with forceful lateral stress. This may have been due to poor isometricity of the transferred tendon or generalised ligamentous laxity. Deie et $\mathrm{al}^{15}$ reported good results with isolated reconstruction of the medial patellofemoral ligament using the semitendinosus ligament in adolescents. However, their patients did not have generalised ligamentous laxity or aplasia of the trochlear groove.

Fondren et $\mathrm{al}^{21}$ recommended the modified RouxGoldthwait technique for patients with an increased Qangle, and Marsh et $\mathrm{al}^{22}$ obtained satisfactory results by adding this technique to a lateral retinacular release for recurrent dislocation of the patella in adolescents. In our operative technique, further stability of the patella beyond the range of $70^{\circ}$ or more of knee flexion could be obtained after lateral release, proximal tube realignment, and semitendinosus tenodesis by the addition of a split patellar tendon transfer. We believe that the addition of this transfer to proximal patellar realignment and semitendinosus tenodesis was essential to obtain a final dynamic balance of the patella in the aplastic trochlear groove.

Two patients had marginal skin necrosis which healed after debridement and secondary suture; this may have been because of a lack of subcutaneous tissue or poor quality tissue for repair related to severe ligamentous laxity. We are aware that this is a small study with limited follow-up and none of our patients has reached skeletal maturity, but the results so far are promising. The improvement in the development of the femoral trochlear groove appears to be in response to the recentering of the patella mechanism. We believe that even in the presence of severe ligamentous laxity, development of the trochlear groove can be expected during the remaining growth when the patella is realigned at a young age. Comparison with a series of similar children treated non-operatively would be very useful and long-term follow-up will be necessary to determine whether patellar stability is maintained after skeletal maturity. 
No benefits in any form have been received or will be received from a commercial party related directly or indirectly to the subject of this article.

\section{References}

1. Eilert RE. Congenital dislocation of the patella. Clin Orthop 2001;389:22-9.

2. Bergmann NR, Williams PF. Habitual dislocation of the patella in flexion. $J$ Bone Joint Surg [Br] 1988;70-B:415-19.

3. Crosby EB, Insall J. Recurrent dislocation of the patella: relation of treatment to osteoarthritis. J Bone Joint Surg [Am] 1976;58-A:9-13.

4. Insall J, Bullough PG, Burstein AH. Proximal "tube" realignment of the patella for chondromalacia patellae. Clin Orthop 1979;144:63-9.

5. Beighton P, Solomon L, Soskolne CL. Articular mobility in an African population. Ann Rheum Dis 1973;32:413-16.

6. Erkula G, Kiter AE, Kilic BA, et al. The relation of joint laxity and trunk rotation. J Pediatr Orthop B 2005;14:38-41.

7. Insall J, Salvati E. Patella position in the normal knee joint. Radiology 1971;101:101-4.

8. Baker RH,Carroll N, Dewar FP, Hall JE. The semitendinosis tenodesis for recurrent dislocation of the patella. J Bone Joint Surg [Br] 1972;54-B:103-9.

9. Kujala UM, Jaakola LH, Koskinen SK, et al. Scoring of patellofemoral disorders. Arthroscopy 1993;9:159-63.

10. Schottle PB, Scheffler SU, Schwark A, Weiler A. Arthroscopic medial retinacular repair after patellar dislocation with and without underlying trochlear dysplasia: a preliminary report. Arthroscopy 2006;22:1192-8.

11. Dejour H, Walch G, Neyret P, Adeleine P. Dysplasia of the femoral trochlea. Rev Chir Orthop Reparatrice Appar Mot 1990;76:45-54 (in French).

12. Arendt EA, Fithian DC, Cohen E. Current concepts of lateral patella dislocation. Clin Sports Med 2002;21:499-519.

13. von Knoch F, Böhm T, Bürgi ML, von Knoch M, Bereiter H. Trochleaplasty fo recurrent patellar dislocation in association with trochlear dysplasia: a 4- to 14year follow-up study. J Bone Joint Surg [Br] 2006;88-B:1331-5.

14. Benoit B, Laflamme GY, Laflamme $\mathbf{G H}$, et al. Long-term outcome of surgicallytreated habitual patellar dislocation in children with coexistent patella alta: minimum follow-up of 11 years. J Bone Joint Surg [Br] 2007:89-B:1172-7.
15. Deie M, Ochi M, Sumen Y, et al. Reconstruction of the medial patellofemoral ligament for the treatment of habitual or recurrent dislocation of the patella in children. J Bone Joint Surg [Br] 2003;85-B:887-90.

16. Steiner TM, Torga-Spak R, Teitge RA. Medial patellofemoral ligament reconstruction in patients with lateral patellar instability and trochlear dysplasia. Am J Sports Med 2006:34:1254-61.

17. Hall JE, Micheli LJ, McManama GB Jr. Semitendinosus tenodesis for recurrent subluxation or dislocation of the patella. Clin Orthop 1979;144:31-5.

18. Letts RM, Davidson D, Beaule P. Semitendinosus tenodesis for repair of recurrent dislocation of the patella in children. J Pediatr Orthop 1999;19:742-7.

19. Chen SC, Ramanathan EB. The treatment of patellar instability by lateral release. J Bone Joint Surg [Br] 1984;66-B:344-8.

20. Dougherty J, Wirth CR, Akbarnia BA. Management of patellar subluxation: a modification of Hauser's technique. Clin Orthop 1976;115:204-8.

21. Fondren FB, Goldner JL, Bassett FH 3rd. Recurrent dislocation of the patella treated by the modified Roux-Goldthwaite procedure: a prospective study of forty-seven knees. J Bone Joint Surg [Am] 1985;67-A:993-1005.

22. Marsh JS, Daigneault JP, Sethi P, Polzhofer GK. Treatment of recurrent patellar instability with a modification of the Roux-Goldthwait technique. J Pediatr Orthop 2006;26:461-5

23. Mendez AA, Keret D, MacEwen GD. Treatment of patelllofemoral instability in Down's syndrome. Clin Orthop 1988;234:148-58.

24. Gordon JE, Schoenecker PL. Surgical treatment of congenital dislocation of the patella. J Pediatr Orthop 1999;19:260-4.

25. Aglietti P, Buzzi R, De Biase P, Giron F. Surgical treatment of recurrent dislocation of the patella. Clin Orthop 1994;308:8-17.

26. Hughston JC, Walsh WM. Proximal and distal reconstruction of the extensor mechanism for patellar subluxation. Clin Orthop 1979;144:36-42.

27. Galeazzi R. Nuove applicazioni del trapianto musculare e tendineo. Ard Di Orthop Milano 1922;38:315-23 (in Italian).

28. Dandy DJ, Griffiths D. Lateral release for recurrent dislocation of the patella. J Bone Joint Surg [Br] 1989:71-B:121-5. 